Check for updates

\section{London}

Cite this as: BMJ 2021;372:n357 http://dx.doi.org/10.1136/bmj.n357 Published: 5 February 2021

\title{
Covid-19: Black people over 80 in England are half as likely as white people to have been vaccinated
}

\section{Adrian O'Dowd}

Targeted activity might be needed to tackle the disparities in accessing covid-19 vaccines, authors of a large study have said after finding that ethnic minorities, people living in areas of high deprivation, and those with severe mental health illness or learning disabilities seem to be less likely to have been vaccinated. ${ }^{1}$

Between 8 December 2020 and 13 January of this year, $41 \%$ of people aged 80 and over in England who do not live in care homes were vaccinated against covid-19. But the researchers from the University of Oxford and the London School of Hygiene and Tropical Medicine found a sizeable divergence in vaccination by ethnicity within this group of 476375 people (of 1160062 over 80 ). While $42.5 \%$ of white people were vaccinated, only $20.5 \%$ of black people and $27 \%-29.5 \%$ of people of mixed, other, and South Asian ethnicities were. The other $39.7 \%$ were of unknown ethnicity.

Another disparity was seen when considering deprivation $-44.7 \%$ of people living in the most affluent areas had been vaccinated compared with $37.9 \%$ of people living in the poorest areas. Patients with pre-existing medical conditions were equally likely, or more likely, to have received a vaccine across most comorbidity groups, with two exceptions-severe mental illness and learning disability. The analysis was carried out on behalf of NHS England and is published as a non-peer reviewed preprint.

The study's principal investigator Ben Goldacre told The BMJ: "We are only describing the disparity in vaccination rates between different groups and we cannot explain them. Nonetheless, it's fair to say this is either vaccine hesitancy in choosing whether or not to have the vaccine or issues around the logistics of how the vaccination programme is rolled out, or a mixture of the two. The ethnicity gap that we are seeing is consistent with the gap that has been observed in previous vaccination campaigns of different vaccines for different diseases.”

He said that it was early days for the UK vaccination campaign but added: "The coverage that has been achieved is nothing short of miraculous.” The researchers are looking at the data in more detail on a fortnightly basis to see if they can identify patterns or explanations for their observations.

"It's clear that a lot is changing very quickly and, for example, with the early signals we saw where people with severe mental illness or learning disabilities were less likely to receive a vaccine, there's some evidence that that's improving over time," said Goldacre.
The authors said that live data monitoring could help support healthcare workers make operational decisions around vaccine rollout. They said that targeted activity might be needed to tackle lower vaccination rates among certain groups.

Goldacre said: "We are providing these data as a service to help people and identify problems and fix them early in a very fast moving vaccination programme. We are happy in principle to consider giving local teams access to local summary data."

Fellow study author Stephen Evans told The BMJ: "This is a very dynamic situation. We have seen changes in the pattern over the first weeks. Enormous amounts of work have been done by individual GPs and very many others to get as many people vaccinated as possible. It is possible that hesitancy or fears may impact some people's wish to have a vaccine but data on that will have to come from others."

1 MacKenna B, Curtis H, Goldacre B, et al. Trends, regional variation, and clinical characteristics of COVID-19 vaccine recipients: a retrospective cohort study in 23.4 million patients using OpenSAFELY. MedRxiv [Preprint]. doi: 10.1101/2021.01.25.21250356. https://www.medrxiv.org/content/10.1101/2021.01.25.21250356v2

This article is made freely available for use in accordance with BMJ's website terms and conditions for the duration of the covid-19 pandemic or until otherwise determined by BMJ. You may use, download and print the article for any lawful, non-commercial purpose (including text and data mining) provided that all copyright notices and trade marks are retained. 